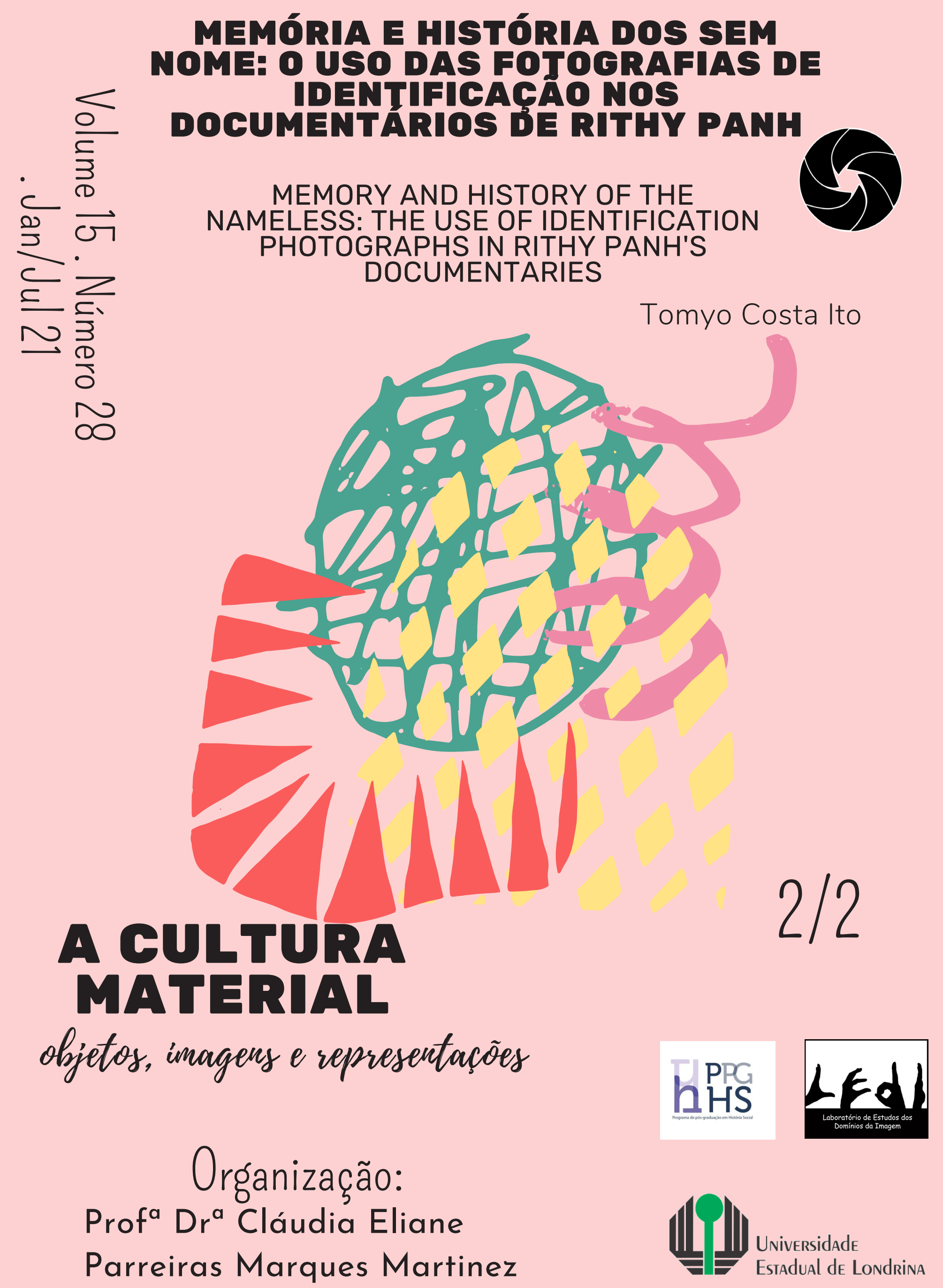




\section{Memória e história dos sem nome: o uso das fotografias de identi- ficação nos documentários de Rithy Panh}

\section{Memory and history of the nameless: the use of mug shots in Rithy Panh's documentaries}

\section{Tomyo Costa Ito ${ }^{1}$}

Resumo: Este trabalho analisa a retomada das fotografias de identificação tiradas na prisão S-21 em quatro documentários de Rithy Panh: Bophana, a cambodian tragedy (1996), S-21: The Khmer Rouge Killing Machine (2002), Duch, The Master of the Forges of Hell (2011) e The Missing Picture (2013). Buscamos analisar as variações dos procedimentos cinematográficos da retomada das fotografias, considerando-as como exercício incessante de interpretação dentro da própria forma fílmica que não toma os sentidos dos arquivos como dados, mas construídos pelos recursos expressivos do documentário. Partindo dos filmes em direção à teoria, aproximamos nossas análises as reflexões sobre a narrativa da história de Walter Benjamin, Theodor W. Adorno, Márcio Seligmann-Silva e Jeanne Marie Gagnebin, para pensar de que modo os documentários fazem uma elaboração do passado e uma recomposição da memória por meio da figura cinematográfica de nomeação.

Palavras-chave: Documentário; Fotografia; História; Memória.

Abstract: This paper analyzes the reuse of mug shots taken in S-21 prison in four documentaries directed by Rithy Panh: Bophana, une tragédie cambodgienne (1996), S-21: la machine de mort khmère rouge (2002), Duch, le maître des forges de l'enfer (2011) and L'image manquante (2013). We seek to analyze the variations of the cinematographic procedures on the reuse of the photographs, considering the unceasing exercise of interpretation within the cinematic form. We consider the sense of the archives not univocal but constructed by the expressive means of the documentary. From the films towards the theory, these analyzes aim to approach the narrative of history on the writings of Walter Benjamin, Theodor W. Adorno, Márcio Seligmann-Silva, and Jeanne Marie Gagnebin, to answer how the documentaries achieve an elaboration of the past and a recomposition of memories through the cinematographic figure of nomination.
${ }^{1}$ Doutorando no Programa de Pós-Graduação em Comunicação Social da Universidade Federal de Minas Gerais (PPGCOM-UFMG), na linha de pesquisa Pragmáticas da Imagem, na cidade de Belo Horizonte, MG. 0 presente trabalho foi realizado com apoio da Coordenação de Aperfeiçoamento de Pessoal de Nível Superior - Brasil (CAPES) - Código de Financiamento 001. Bolsista da Capes/ PDSE - Processo n88881.189166/2018-

01. tomyocostaito@ gmail.com. ORCID iD: https://orcid. org/0000-0002-00667636.

Keywords: Documentary; Photography; History; Memory. 
${ }^{2}$ No início de 1979, o regime foi derrubado

Documentários que trabalham com a retomada de acontecimentos históricos têm como procedimento frequente o uso de materiais de arquivo. $\mathrm{Na}$ retomada desses materiais são desconsiderados, muitas vezes, os contextos específicos da tomada - o momento de gravação das imagens e dos sons. Quando as imagens são produzidas em períodos de acontecimentos traumáticos e violentos, durante regimes ditatoriais marcados pela censura, tortura, assassinatos e genocídios, torna-se fundamental a reflexão sobre o modo de sua retomada. As fotografias de identificação são um produto comum desses regimes e constituem-se como rastros destes passados terríveis. Os filmes Retratos de Identificação (2014), de Anita Leandro e 48 (2009), de Susana de Sousa Dias são exemplos de documentários que retomam as fotografias de identificação e propõem, pelo exercício da forma fílmica, o pensamento sobre seus sentidos na busca da recomposição de memórias apagadas pela historiografia oficial, muitas vezes, conduzidas pelas democracias liberais que parecem sempre buscar saída na ideia de reconciliação.

Os documentários de Rithy Panh utilizam o procedimento, entre tantos outros, de uso de arquivos para a construção da memória cambojana, sistematicamente apagada pelo regime do Khmer Vermelho nos anos 1970 e denegada por seus atuais governantes em nome de uma reconciliação ${ }^{2}$. O percurso cinematográfico do cineasta é atravessado por um "trabalho de arquivista" (LEANDRO, 2016) que o levou a fundar, em 2006, o Bophana, centre de ressources audiovisuelles, na capital Phnom Penh. Este texto analisa, especificamente, no percurso dos documentários de Panh, a "retomada” (LINDEPERG, 2010) das fotografias de identificação tiradas na prisão S-213. Nosso objetivo é investigar as variações dessa retomada em quatro filmes do cineasta que em sua trajetória toma os arquivos como material para um exercício contínuo de produção de sentidos por meio dos recursos expressivos do documentário. Dessa forma, ele não retoma o passado como algo acabado, mas faz de seus rastros o material para construção cinematográfica da memória cambojana e a reescrita de sua história. Em particular, acreditamos que os usos desses arquivos colaboram para a construção de uma figura cinematográfica a qual denominamos nomeação, pois esforça-se em nomear e ressingularizar os mortos, os vencidos (antes anônimos na quantificação terrível de dois milhões de assassinados) e esforça-se em buscar uma nomeação do genocídio através dos testemunhos dos sobreviventes e dos carrascos. Nesse sentido, iremos aproximar as análises dos filmes às reflexões sobre a narrativa da história de Walter Benjamin, Theodor W. Adorno, Márcio Seligmann-Silva e Jeanne Marie Gagnebin.

\section{A TOMADA E A RETOMADA DOS ARQUIVOS} pelos vietnamitas que ocuparam o país até o fim da década de 1980. Durante esse período, o Kampuchea Democrático manteve seu reconhecimento e sua cadeira na $\mathrm{ONU}$ e parte do país permaneceu ocupado pelo seu exército. Os Tratados de Paz de Paris, firmados em 1991 contaram, ainda, com a representação do Khmer Vermelho e a palavra genocídio não foi sequer mencionada nos textos, tampouco os campos de extermínio haviam sido reconhecidos pela ONU. Defendendo a reconciliação, o governo recém-formado nos anos 1990 não vai prender nem julgar nenhum membro do regime. Essa postura política dos governantes do país e o trauma vivido pelos cambojanos - que, em certa medida, desejavam esquecer aqueles horrores -, criaram resistências aos filmes de Rithy Panh. Bophana, une tragédie cambodgienne (1996), primeiro filme do cineasta a abordar diretamente o regime do Khmer Vermelho, conviveu com correntes políticas do país que defendiam o fechamento do Museu do Genocídio de Tuol Sleng. Foi apenas no dia 6 de junho de 2003 que a ONU e o governo do Camboja assinaram um acordo para criar 
Sylvie Lindeperg (2018a, tradução nossa ${ }^{4}$ ) define a imagem de arquivo como "[...] a expressão de um ponto de vista que é, ao mesmo tempo, um arquivo das maneiras de filmar, de apreender o mundo, de lançar um olhar sobre seus contemporâneos”. Como enfatiza a pesquisadora, a imagem de arquivo é um importantíssimo material de estudo da história. Apesar disso, o trabalho de interpretação das imagens tem entrado de forma tímida e lenta no pensamento sobre a história, e ainda sofre de um "duplo curto-circuito”: a ilusão de que a imagem de arquivo faz vir o passado diretamente, e o comentário sem controle, que abusa dos documentos ao desconsiderar seu contexto de origem. Essas interpretações discutíveis das imagens de arquivo vão aparecer em documentários históricos produzidos pelas grandes indústrias de televisão que vendem a ilusão de trazer "o passado como de fato foi" próprias imagens, seus contextos e suas estratégias de produção. $\mathrm{O}$ efeito de presença produzido pelo visível de um passado que não existe mais pode levar a uma negligência do criterioso trabalho de interpretação das imagens, o que para Lindeperg (2018b, p. 204) é indispensável. O uso das imagens de arquivo exige, portanto, uma reflexão ética quando trabalhamos em um terreno de disputas da escrita da história, da construção da memória do passado. Rithy Panh constrói essa postura ética ao demarcar, na escritura mesma dos filmes, as maneiras de se usar e tratar as imagens de arquivo.

Assim, para Sylvie Lindeperg, o estudo do uso dos arquivos pelo cinema exige uma visada dupla sobre dois momentos constitutivos da imagem de arquivo: a tomada, ou seja, a gravação da imagem, e a retomada, que é a reutilização dessa imagem pelo documentário. Para a autora, não se pode trabalhar com a retomada sem perguntar-se sobre esse primeiro momento e sobre a lógica inscrita no olhar de quem fez a filmagem. Pois, apesar de haver uma ordem que guia o momento de gravação, a retomada dos arquivos pelos cineastas pode revelar novos sentidos e levá-los a uma nova maneira, de ver esse processo, não prevista pelo realizador da tomada. Ao tratar dos filmes produzidos, por encomenda, pelos nazistas nos guetos judeus, ela ressalta a necessidade de investigar o momento da tomada:

Não se pode trabalhar com a "retomada" dessas imagens e da utilização delas sem interrogar esse momento único que é a "tomada". Ou seja, o que é irredutível no olhar do fotógrafo ou do diretor de fotografia nazista mas, também o que resiste, às vezes, na imagem e que se revela com o passar do tempo e de suas reutilizações (LINDEPERG, 2010, p. 319).

\section{O CONTEXTO DA TOMADA}

Para entendermos o contexto geral da "tomada" dos retratos de identificação, precisamos compreender as condições do surgimento de técnicas de controle dos corpos na modernidade. Tom Gunning argumenta que as "técnicas de circulação" definem as um tribunal especial para julgar os antigos líderes do Khmer Vermelho e só teve início em 2006, quatro anos após o lançamento de S21, la machine de mort khmère rouge (2002). Apenas cinco líderes do Kampuchea Democrático foram indiciados e presos pelos crimes de genocídio, crimes contra a humanidade e crimes de guerra: eles são Nuon Chea, Khieu Samphan, leng Sary, leng Thirith e Kaing Guek Eav. Este último, também conhecido pelo codinome Duch, foi secretário do Partido e diretor da prisão S21.

${ }^{3}$ S21 foi um centro secreto de tortura e extermínio, localizado na capital Phnom Penh, que causou a morte de pelo menos 12.380 pessoas. No local, foi criado o Museu do Genocídio de Tuol Sleng, em 1980. Lá, antes do regime, funcionou a escola secundária Tuol Svay Prey.

4 "[...] l'expression d'un point de vue en même temps qu'elle est une archive des manières de filmer, d'appréhender le monde, de porter un regard sur ses contemporains".

5 Para retomar a importante formulação de Walter Benjamin (1996, p. 224) nas Teses sobre o conceito de história: "Articular historicamente o passado não significa conhecê-lo como de fato foi". 
transformações da modernidade, pensadas como uma mudança na experiência. A estrada de ferro seria a primeira imagem dessa transformação: a rapidez de circulação, a diminuição de distâncias produzem uma "nova experiência do corpo e da percepção do ser humano".

\begin{abstract}
Em todos esses novos sistemas de circulação, delineia-se o drama da modernidade: um colapso das experiências anteriores de espaço e de tempo por meio da velocidade; uma extensão do poder e da produtividade do corpo humano e a consequente transformação deste por meio de novos limiares de demanda e perigo, criando novas formas de disciplina e regulação corporais com base em uma nova observação (e reconhecimento) do corpo (GUNNING, 2001, p. 34).
\end{abstract}

A reprodutibilidade e a circulação tornam a fotografia uma expressão da experiência moderna em que há uma tensão entre as compreensões tradicionais de identidade e a facilidade e a rapidez da circulação que desfazem essas compreensões. Ao mesmo tempo em que a fotografia participa desse processo de desmoronamento da identidade, ela vai servir como instrumento dos sistemas de regulação do corpo. No entanto, uma das conclusões do autor é que a fotografia não pode funcionar como instrumento de regulação sem estar associada a um sistema de conhecimento: é preciso lançar mão da classificação para torná-la uma informação convincente e utilizável. A junção de um conjunto de informações sistematizadas com (ou mesmo sem) a fotografia produziu arquivos de informação que serviam como instrumentos de controle na sociedade moderna. Estes sistemas foram utilizados, em grande parte, pelo processo de investigação e controle policial e foram reelaborados pela ficção policial moderna. Um dos sistemas mais influentes de classificação de criminosos foi desenvolvido pelo estatístico da polícia francesa Alphonse Bertillon que definiu formas fixas de recolhimento de informações que produziam "séries limitadas de variáveis" e permitiram individualizar um criminoso dentro de um grande número de pessoas.

\footnotetext{
Bertillon defendia que a simples posse da imagem de um criminoso podia ser inútil ou no mínimo difícil de manejar. Primeiro, ele sistematizou o processo da fotografia policial. Padronizou a distância entre a câmera e o sujeito; criou uma cadeira especial na qual o sujeito sentaria e que controlaria a posição e a postura; determinou o tipo de lentes, introduzindo assim um enquadramento mais próximo e constante, e estabeleceu os ângulos frontais e de perfil diretos da agora familiar foto de identificação policial. Esses procedimentos deram à fotografia criminal uma uniformidade que facilitou seu uso como informação e evidência. Além disso, estabeleceram o emprego da fotografia como um processo disciplinar, afirmando o poder do sistema sobre o corpo e a imagem do criminoso. O sistema determinou a expressão e a postura na fotografia; o criminoso simplesmente entregava a facticidade do seu corpo (GUNNING, 2001, p.49).
}

Estes procedimentos tinham um papel importante na regulação dos corpos, pois os reduziam a uma série limitada de variáveis com o intuito de possibilitar a identificação. Como afirma Gunning (2001, p. 53) o corpo não só é gravado, mas é, também, filtrado 
“segundo um novo vocabulário padronizado de descrição e classificação”. Estes mesmos procedimentos serão utilizados por forças policiais de repressão, no Brasil, em Portugal, no Camboja (e em muitos outros países) durante regimes ditatoriais, na produção dos arquivos de informações de presos políticos, cada um com a suas especificidades de classificação ${ }^{6}$.

No contexto particular do regime do Khmer Vermelho, na prisão S-21, as fotografias de identificação das prisioneiras e dos prisioneiros eram tiradas no momento de sua chegada na prisão e eram acompanhados de um procedimento similar de classificação, como os próprios filmes de Panh indicam. As prisioneiras e os prisioneiros tinham de fornecer informações detalhadas sobre suas vidas e o motivo de suas prisões. Uma cadeira com a mesma função do sistema de Bertillon para controlar o fotografado é vista em cena no filme S-21: la machine de mort khmère rouge (2002). Havia um minucioso trabalho de catalogação e tabulação dessas informações: a idade, a cidade de origem, o trabalho exercido, entre outras informações que eram analisadas pelo diretor da prisão. Para esses relatórios eram criadas "séries limitadas de variáveis" com o intuito de "conhecer" os inimigos do regime. Na documentação preservada, é possível ver anotações escritas pelo próprio diretor da prisão, ordenando o interrogatório, a tortura, a eliminação ou mesmo o pedido de "guardar para uso", caso julgasse que o trabalho exercido pelo preso fosse de alguma utilidade. Os presos também eram classificados, por exemplo, como pertencentes à Agência Central de Inteligência dos EUA (CIA), ao Comité de Segurança do Estado da extinta União Soviética (KGB) ou às forças inimigas do Vietnã ${ }^{7}$.

A partir dessa breve perspectiva sobre as intenções das tomadas, vamos analisar quatro filmes de Rithy Panh e o modo como retomam os retratos de identificação, sendo eles: Bophana, une tragédie cambodgienne (1996), S-21: la machine de mort khmère rouge (2002), Duch, le maître des forges de l'enfer (2011) et L'image manquante (2013). Buscamos ressaltar, nos filmes, o trabalho de nomeação dos mortos e do próprio acontecimento catastrófico.

\section{O RETRATO TEM UM NOME}

No filme Bophana, une tragédie cambodgienne, M. Toeuth, tio de Bophana, percorre o mural dos retratos de identificação expostos no Museu do Genocídio de Tuol Sleng. A fotografia permite-lhe identificar e confirmar que aquela era mesmo sua sobrinha. Sem engano, aquele rosto é de Hout Bophana, o retrato é nomeado. A câmera enquadra em plano detalhe o rosto da mulher. $O$ formato do rosto na imagem faz com que o tio recorde de seu último encontro com ela. Ele compara e contrasta a forma arredondada da época de colegial, uma lembrança feliz de seu rosto, com a feição que ele viu pela última vez, com as faces sem vida no encontro que tiveram, logo após a queda
${ }^{6}$ Cabe ressaltar que a produção de arquivos de informação para identificação das populações nacionais é um procedimento habitual e bastante aceito, como é o caso do documento de identidade e de passaporte. Um grupo enorme de informações via sistemas digitais e móveis cresce e circula de forma cada vez mais veloz e ampla, construindo novas dinâmicas de percepção e experiência.

7 Em grande parte dos casos a ligação dos prisioneiros com essas organizações eram fantasiosas. Seus próprios carrascos os obrigavam a confessar e inventar crimes cometidas contra o regime. Era imperativo que houvesse algum tipo de confissão e as torturas apenas cessavam quando isso acontecia. 
Naquele momento, ambos estavam tristes, diz ele. Seu testemunho prossegue com o seu olhar voltado para a fotografia, ele pouco desvia o olhar e sua fala expressa o lamento de não ter chamado sua sobrinha para morar com ele. $\mathrm{Na}$ ocasião, eles não puderam trocar uma palavra, pelo medo de serem mortos pelos soldados que os vigiavam. O tio parece dizer para Bophana aquilo que não pôde na época. Ao pensar sobre o sofrimento de sua sobrinha na prisão, Toeuth não consegue dar continuidade ao seu testemunho, mas é a partir dele que o filme prossegue.

Neste filme, Rithy Panh escolhe pôr uma forma mais explícita de nomeação, a fotografia de Bophana, identificada por seu tio nos primeiros minutos do filme, vai guiar a narrativa do documentário, contada por uma voz over, e relatar toda a trajetória particular de sofrimento, mas também de resistência da jovem mulher. Um de seus atos de resistência foi escrever cartas de amor ao seu marido, durante um regime que proibia qualquer expressão individual e o preço foi sua morte.

Outra cena em que figuram as fotografias de identificação é intercalada por duas importantes sequências que vão orientar os procedimentos dos próximos filmes de Panh: o encontro entre Him Houy (ex-guarda de S-21) e Vann Nath (sobrevivente de S-21) e, depois, o testemunho de Him Houy sobre as torturas e assassinatos dos prisioneiros. Trata-se da cena do mural de fotografias, em uma suave panorâmica, sugere a dimensão do genocídio ao mostrar o vasto número de fotografias que se estendem por diversas paredes das salas do Museu. No fim de seu movimento, a câmera vai se aproximar de uma pequena porção das fotografias, no centro delas Bophana. Trata-se de singularizar as histórias, sem perder de vista sua dimensão coletiva. Na recomposição da memória cambojana é preciso dar nome ao mortos.

No fim do filme, a fotografia é utilizada, ao lado de uma cartela, com algumas informações classificadas pelo regime, entre elas, a data de "destruição" do corpo de Bophana. A mesma fotografia irá retornar nos filmes seguintes de Rithy Panh em diferentes situações e, em muitas delas, não será claramente contextualizada como neste filme.

\section{A FOTOGRAFIA PERMITE AOS CARRASCOS DAR UM NOME}

No filme S-21: la machine de mort khmère rouge (2002) os antigos guardas da prisão reencenam o cotidiano nesse local a partir de suas memórias reativadas pelo encontro entre eles, pelo encontro com o espaço físico do Museu e pelos encontro com os documentos, entre eles, os retratos de identificação. Nas primeiras sequências do filme dentro da prisão, os guardas se declaram como vítimas, estão conformados com a posição impotente daquele que apenas obedeceu às ordens dos seus superiores. $\mathrm{O}$ contato
(1998), os códigos museográficos da exposição são separados em três categorias: a primeira categoria é chamada de informações básicas, composta por cenários, vitrines, painéis ilustrativos e tablados; a segunda são informações argumentativas, com textos gerais e textos-legenda; por último, a terceira categoria é formada por informações complementares, com etiquetas nominativas, mapas e gráficos. 
com o espaço físico, os relatórios e as listas de prisioneiros, informações fortemente ligadas às questões de organização, planificação e execução do trabalho dentro da prisão geram reações, palavras e gestos que repetem de forma automatizada o modo como os guardas conduziram o trabalho na prisão na época de seu funcionamento. Nestes relatórios também estão presentes fotografias dos cadáveres de prisioneiros mortos durante as sessões de torturas ou que conseguiram se matar por um descuido dos guardas. Novamente, essas fotografias levam os guardas a repetição automatizada de palavras de ordem, pois talvez remetam ao cumprimento de uma missão em que não se podia falhar, pois não era permitido matar um preso durante a tortura, podendo o responsável sofrer sanções. Em um retrato da morte é pouco o que resiste na imagem, quando ela não é articulada com outras.

Já as fotografias de identificação, em que os prisioneiros e prisioneiras encaram a câmera, terão um importante papel em modificar as formas de testemunho dos carrascos, da mesma forma, a presença do sobrevivente Vann Nath irá produzir novas relações. Em uma das cenas do filme, Prak Khan, antigo torturador, é levado a falar diante do retrato de identificação de uma moça, Nay Nan. Panh não faz perguntas a ele, não utiliza o formato de entrevista. Vann Nath, pintor e sobrevivente da prisão S-21, é quem faz o papel de mediador e questiona o testemunho de Prak, concedendo uma temporalidade à escuta, mas sem interrompê-lo. O modo de construção da cena dá ao antigo torturador um espaço de fala em que seu ritmo e sua respiração são preservados. Por sua vez, o arquivo fotográfico da moça não possui mais a sua finalidade original: o controle. A imagem da prisioneira, tal como é retomada e reconfigurada pelo filme, torna-a uma agente ativa neste encontro com seu carrasco, sua fotografia confere-lhe a potência de o interpelar.

Sylvie Rollet (2013, p. 200), tendo em vista os usos dos arquivos, afirma que os filmes de Rithy Panh trabalham para a "recomposição de uma contra-memória do acontecimento genocida”. As fotografias de identificação que fizeram parte do sistema de apagamento da memória promovido pelo Khmer Vermelho ganham novos sentidos. Para que os retratos de identificação ocupassem novos lugares, a autora ressalta a importância do encontro entre as fotografias e os carrascos: "Contribuindo para definir um campo de visão comum, essas fotografias vão dar aos carrascos a oportunidade de 'ver' enfim o que eles não viam e de nomear o que não tinha nome” (ROLLET, 2013, p. 212; grifo da autora). Ela também aborda os movimentos da câmera que enquadram com atenção as fotografias, que, por sua vez, lançam um olhar ao espectador durante os testemunhos dos carrascos. Tais operações provocadas na construção da mise-en-scène do filme subvertem a intenção inicial da fotografia de uma jovem anônima: "lá onde o operador Khmer Vermelho gravava uma série, Rithy Panh reintroduz uma singularidade, mais insistente na medida em que seu olhar para nós permanece anônimo" (ROL- 
LET, 2013, p. 226). A fotografia lança um olhar, não apenas ao carrasco, mas também a nós: “O regime 'ético' da fotografia não clama mais somente nosso julgamento, mas nossa responsabilidade" (ROLLET, 2013, p. 226, grifo da autora).

Ainda que haja a nomeação da jovem Nay Nan, diferentemente do filme anterior analisado, as fotografias não são nomeadas de forma direta. Este é o caso do retrato de identificação de Bophana que está presente em meio aos relatórios e aparece algumas vezes em cena, embora não haja uma menção direta a sua história particular. É de uma outra maneira que as fotografias terão um nome próprio, dessa vez, por meio de um papel muito mais ativo na produção da mise-en-scène, pois elas vão desencadear o testemunho de sobreviventes e dos guardas da prisão. A presença do material, nem sempre acompanhados de uma contextualização explícita, confere uma força de indeterminação aos retratos. Eles não estão ali para ilustrar o testemunho dos guardas, mas para, justamente, abrir um espaço de sentido dentro do filme. O olhar das vítimas excede a exposição dos fatos e perturba a resignação dos guardas. Sua força de indeterminação vem dessa impossibilidade de darmos conta da presença da fotografia, tanto para nós espectadores quanto para aqueles que são convocados a falar a partir delas. Não é apenas as vítimas que não tem nome, mas é a própria história dos acontecimentos. Nomeá-lo de genocídio de dois milhões de mortos não é suficiente, é preciso singularizar as histórias das vítimas. Para tal, é necessário um esforço contínuo. A repetição dos encontros com os retratos vão perturbar a resignação dos carrascos, possibilitando que eles deem um nome ao genocídio.

\section{AS FOTOGRAFIAS NO CONFRONTO COM AS PALAVRAS DE ORDEM}

No filme Duch, le maître des forges de l'enfer (2011), o material de arquivo terá um papel ativo no confronto com o testemunho do ex-diretor da prisão S-21. A sua retomada vai constituir o dispositivo do filme: Kaing Guek Eav, sentado em uma mesa, explica o funcionamento da máquina de morte, da qual ele foi um dos idealizadores, a partir dos arquivos ${ }^{8}$ entregues a ele por Rithy Panh.

$\mathrm{Na}$ mise-en-scène, observamos o corpo, o rosto e os gestos do ditador nas situações em que ele está diante das fotografias de identificação; na montagem, observamos o encadeamento do plano de seu corpo e do contraplano dos retratos e, também, de suas aparições em planos de curta duração. Interessa-nos o modo como as contínuas variações desses elementos, o corpo de Duch, sua fala e os arquivos confrontam seu testemunho e intensificam sua aparição, reforçando os sentidos de sua posição política. Assim como os retratos tiveram um efeito provocador mais intenso nos testemunho dos guardas, Duch também se diz muito incomodado diante deles, embora ele fale com muita frieza em certos momentos. E, da mesma forma que no filme anteriormente ana-
${ }^{8}$ Relatórios de controle da situação dos presos, listas de prisioneiros executados, fotografias de identificação, as autobiografias e confissões escritas pelos prisioneiros contra à sua vontade durante as torturas, fotografias dos encontros do partido do Khmer Vermelho. Estes materiais foram produzidos, em grande parte, dentro da prisão S21, sob o comando de Duch. 0 dispositivo também irá colocar Duch diante das imagens filmadas por Panh em seu longo trabalho de escuta dos testemunhos de sobreviventes do regime e, também, de soldados e oficiais do regime do Khmer Vermelho que cometeram atrocidades contra os próprios cambojanos. Este trabalho de historiador e arquivista, realizado dentro de seus filmes, em especial, S21: la machine de mort khmère rouge (2002), em uma filmagem que prosseguiu por três anos e, também, fora de seus filmes por meio de seu trabalho no Bophana, centre de ressources audiovisuelles. 
lisado, ao ler os relatórios, Duch se entrega a repetição das palavras de ordem do partido e se preocupa em explicitar seu modo de organização dos documentos da qual ele se mostra orgulhoso.

Em um plano fechado de Duch, ele diz: "Eu disse ao camarada Hor e ele ficou feliz: 'Construa pequenas celas, como aquelas que nossos inimigos nos trancavam'”. A câmera faz um movimento para baixo para enquadrar a fotografia de uma prisioneira sentada com um bebê ao seu lado em uma pequena cela. Duch segura a fotografia em suas mãos, mostrando-a para a câmera, ele continua: “Assim eles não vão poder conversar entre si'. Hor disse: 'ok, grande irmão'. E ele as construiu. Eu deixava ele prender as pessoas. Eu nunca as visitava”. Duch utiliza a fotografia da prisioneira de uma forma bastante fria para ilustrar de que modo a arquitetura de S-21 funcionava. Na sequência seguinte, Duch está cercado de fotografias que estão em cima da mesa. Ele pega uma delas e diz:

Eu fico aterrorizado apenas por olhar esta fotografia. De todas as fotografias, esta é a que mais me aterroriza. E se eu encontrasse alguém que eu conhecia? Eu era sempre evasivo. Eu sempre olhava para o lado. Eu não ajudei ninguém. Quem morre, quando e onde? Eu confiava isso ao karma. Apenas jogue-os fora!

Dessa vez, Duch não mantém a mesma postura fria e se diz incomodado com os retratos, mas em sua fala fica evidente sua indiferença com os prisioneiros. "Apenas jogue-os fora!", diz ele. Cabe ressaltar, ainda, que Duch pouco olha diretamente para as fotografias, ele prefere virá-las para a câmera.

As fotografias de identificação também aparecem em planos bem curtos que relampejam sobre o discurso de Duch, além de sua curta duração, essas imagens não são contextualizadas o que dá destaque a imagem em si mesma, a expressão facial dos prisioneiros, seus rostos cansados, seus olhares, por vezes, enigmáticos vão participar do confronto do testemunho do ditador. Cabe destacar que essas imagens nunca são apresentadas graficamente, mas aparecem dentro do contexto da filmagem de S-21: la machine de mort khmère rouge (2002), sendo seguradas pelas mãos dos sobreviventes, dos guardas ou mesmo por um movimento de câmera dentro do espaço do Museu do Genocídio. Dessa forma, essas imagens vêm já carregadas de uma experiência anterior de testemunho diante dos arquivos.

As associações criadas na montagem vão compor espaços de memória dentro do filme: os relatórios, as fotografias, os filmes, os testemunhos, as histórias dos anônimos que figuram nas fotos e nos próprios escritos de Duch. Anita Leandro trata da resistência do ditador em testemunhar, em assumir sua responsabilidade e de encarar os olhares lançados por aqueles e aquelas que foram fotografados e, mais tarde, assassinados sob sua ordem. A autora retoma um comentário de Rithy Panh: quando questionado por Duch sobre a serventia de lhe mostrar as fotografias, o cineasta responde que os mortos 
ouvem o testemunho do ditador.

Se Duch é incapaz de confessar a verdade, sua mudez, suas mentiras e perjúrios tornam-se mais evidentes diante desses rostos de prisioneiros que o interpelam. Dos interstícios de sua fala repetitiva, pois sempre relançada com o auxílio das mesmas imagens, emerge um testemunho vivo, nunca antes formulado, proveniente da relação direta do antigo chefe de polícia com os documentos que ele produziu, com os retratos dos mortos que ele eliminou. (LEANDRO, 2013, p. 189-90)

Para Anita Leandro (2016, p. 7), os mortos testemunham por meio dos arquivos: "Graças aos arquivos, os mortos, que, por definição, não podem mais testemunhar, ressurgem, paradoxalmente, entre os vivos, como a testemunha por excelência”. Assim, ainda que o ditador insistisse na denegação, as fotografias confrontam seu testemunho.

\section{O RETRATO ANÔNIMO}

No filme L'image manquante (2013), Rithy Panh faz uma narrativa da vida sob o regime do Khmer Vermelho a partir de suas experiências pessoais, que são, também, coletivas. O cineasta narra por uma voz over, em primeira pessoa e em tom autobiográfico, utilizando bonequinhos de argila, carregados de expressividade, que fazem uma encenação dos acontecimentos. Também são utilizadas imagens de arquivos, muitas delas dos filmes de propaganda do Khmer Vermelho que ele remonta, comenta e relaciona com os outros elementos.

Uma das questões em jogo na elaboração do passado traumático do Camboja e do próprio diretor é como dar o testemunho de uma cena da morte pelo cinema. Uma das escolhas do cineasta é de não mostrar a fotografia de uma execução: "O que mostra uma imagem da morte?", questiona Panh: "Eu prefiro mostrar a imagem de uma jovem mulher desconhecida que desafia a câmera - o olho do carrasco - e ainda olha para nós”. Novamente, Panh retoma o plano do mural de fotografias de identificação exibidas no Museu do Genocídio. Bophana habita, mais uma vez, o filme de Panh. Porém, seu olhar que encara a câmera permanece anônimo. É digno de nota, a não referência ao nome da jovem. Assim, ele não destaca a sua história particular, mas reforça a singularidade de seu olhar anônimo, em gesto oposto ao primeiro filme que analisamos.

Fazer faltar uma imagem, decidir o que não mostrar é dar espaço para uma busca contínua de formas de nomeação. As encenações dos bonequinhos (sempre acompanhadas da narração de Panh) vão mostrar cenas da morte: as crianças que morrem de fome, a execução de prisioneiros no S-21, homens sendo enterrados. Essa operação cinematográfica nos faz ver não a imagem da morte (que poderia criar uma relação de fusão do espectador com a imagem), mas uma experiência da imagem da morte. Em outras palavras, o fora de campo construído pelas encenações com os bonequinhos e a 
narração constroem uma "distância entre o visível e o sujeito do olhar" (MONDZAIN, 2009 , p. 72).

\section{A EXPOSIÇÃO DA CATÁSTROFE PELO DOCUMENTÁRIO}

Ao expor o modo de reflexão sobre as catástrofes do século XX e a possibilidade de sua representação, Seligmann-Silva (2000, p. 73) aponta uma modificação nesta reflexão na modernidade, pois a experiência que caracteriza a catástrofe é percebida como parte do cotidiano. "A experiência prosaica do homem moderno está repleta de choques, de embates com o perigo”. Essa modificação tem consequências para a representação da catástrofe e, em outras palavras, para a sua narrativa histórica. Nesta discussão, a Shoah se apresenta como evento-limite, marcado pelo excesso que caracteriza o choque.

\footnotetext{
O historiador da Shoah fica preso a esse duplo mandamento contraditório: por um lado, a necessidade de escrever sobre esse evento, e, por outro, a consciência da impossibilidade de cumprir essa tarefa por falta de um aparato conceitual 'à altura' do evento, ou seja, sob o qual ele poderia ser subsumido (SELIGMANN-SILVA, 2000, p. 78).
}

Devido a sua especificidade como algo sem limites e irrepresentável, Seligmann-Silva (2000, p. 80) irá apontar para uma aproximação da contemplação desse fato histórico a um registro reservado à arte, reconhecido por ele como a experiência artística do sublime que o autor caracteriza da seguinte forma: "o seu 'excesso', a sua força ofuscante que escurece, na nossa mente, todos os nossos conceitos”. Reserva-se à arte a possibilidade de "expor" esse excesso, essa força não apreensível pela mente.

Do conceito de sublime, Seligmann-Silva (2000, p. 84) aborda o conceito de trauma em Freud que da mesma forma se caracteriza pela "incapacidade de recepção de um evento que vai além dos 'limites' da nossa percepção e torna-se, para nós, algo sem-forma. Essa vivência leva posteriormente a uma compulsão à repetição da cena traumática”. Seligmann-Silva afirma que a aproximação a Freud nos auxilia a pensar de que modo uma representação da Shoah pode colaborar ou não para um trabalho de elaboração, nas palavras do autor, se ela colabora para uma "integração da cena de modo articulado e não mais patológico na nossa vida” (2000, p. 85). Dessa forma, a Shoah põe em questão a objetividade histórica, já que é preciso libertar-se de uma imagem do passado sobre a qual não se tem controle.

Para Adorno, este trabalho de elaboração do trauma consiste em uma autoconsciência crítica que não pode sucumbir ao "esquecimento vazio e frio", devendo buscar a compreensão do passado no presente: "No fundo, tudo dependerá do modo pelo qual o passado será referido no presente; se permanecemos no simples remorso ou se resistimos ao horror com base na força de compreender até mesmo o incompreensível”9 (ADORNO; 2005, p. 100, tradução nossa). Adorno (2005) profere estas palavras a partir
9 "Essentially it is a matter of the way in which the past is made present; whether one remains at the level of reproach or whether one withstands the horror by having the strength to comprehend even the incomprehensible". 
de uma leitura freudiana do conceito de elaboração, convocando a psicanálise no auxílio para o combate à sobrevivência do fascismo.

Jeanne Marie Gagnebin, na esteira de Adorno e Walter Benjamin, ressalta que a elaboração da história deve passar pelo recolhimento das histórias dos sem nome. Para ela, o que deve retornar é a memória "que a história oficial não sabe o que fazer", seu "sofrimento indizível":

aquilo que não tem nome, aqueles que não têm nome, o anônimo, aquilo que não deixa nenhum rastro, aquilo que foi tão bem apagado que mesmo a memória de sua existência não subsiste - aqueles que desapareceram tão por completo que ninguém lembra de seus nomes. Ou ainda: o narrador e o historiador deveriam transmitir o que a tradição, oficial ou dominante, justamente não recorda (GAGNEBIN, 2009, p. 54).

A retomada da fotografia de identificação de Bophana, a atenção aos rostos singulares em meio aos milhões de anônimos assassinados, o esforço para abrir espaços de palavra para os sobreviventes e para carrascos nomearam o que passou, essas são as histórias dos sem nome que Rithy Panh busca ressingularizar em seus filmes.

Seligmann-Silva argumenta que as representações hiper-realistas do campo de concentração não permitem "pôr em perspectiva" essa experiência, pois seu excesso de choques produz uma cisão no $\mathrm{Eu}$, de tal intensidade, que cria uma experiência de irrealidade, ou seja, de negação dos fatos experienciados. Por exemplo, a hiper-realidade da reencenação dos ex-guardas de S-21, quando em contato com os relatórios, põem-se a repetir as palavras de ordem do Khmer Vermelho não permite uma "integração da cena de modo articulado”. Essas repetições devem estar associadas a outras formas de interação entre os guardas, os sobreviventes e os documentos para que possam ganhar algum efeito, propriamente, terapêutico.

A filmografia de Panh, ao insistir na repetição articulada do passado e impedir seu esquecimento, "não significa", de forma alguma, "reconstruir uma grande narrativa épica, heroica da continuidade histórica" (GAGNEBIN, 2009, p. 53). Rithy Panh posiciona-se de forma clara em relação ao seu trabalho cinematográfico que é também histórico. Sua preocupação não é a recomposição de uma história verdadeira, mas um trabalho de "agrimensura da memória", como o próprio cineasta afirma (PANH, 2013). Ao retomarmos, junto com Gagnebin, o modo de retomada do passado de Walter Benjamin que afirma "Articular historicamente o passado não significa conhecê-lo 'tal como ele propriamente foi'. Significa apoderar-se de uma lembrança tal como ela cintila num instante de perigo". Não se trata, portanto, de representar o fato histórico em sua totalidade, não se trata de uma descrição. "Nós articulamos o passado, diz Benjamin, nós não o descrevemos, como se pode tentar descrever um objeto físico" (GAGNEBIN, 2009, p. 40). Aqui, a palavra articulação ganha outros contornos na perspectiva de uma ela- 
boração cinematográfica do passado, essa articulação vai se apresentar por meios dos procedimentos próprios do documentário. Assim, Rithy Panh irá dispor os retratos de identificação, as lembranças e os rastros do passado de diferentes formas, por meio de um trabalho na mise-en-scène e na montagem.

O gesto de colocar em cena as fotografias de identificação resistem à função inicial de controle das "tomadas" realizadas pelos Khmer Vermelho. Não mais em situação de instrumento policial, de uma série montada para o extermínio, agora os rostos podem reclamar um nome, podem provocar encontros, podem servir como agentes que confrontam seu carrasco e podem desencadear a rememoração dos vivos. Se o corpo das vítimas não pode ser resgatado, não pode ser salvo de sua exterminação física, os rastros, o uso dos arquivos combate o esquecimento e a eliminação simbólica. O uso da fotografia vai permitir uma articulação do passado que, nos filmes, favorece aqueles que testemunham saírem da lógica dos mecanismos patológicos de repetição, geralmente, acionados para lidar com um fato histórico que excede à percepção.

Nesta breve trajetória nos filmes de Panh, vimos como que a cada filme o diretor inaugura uma nova forma de expor os retratos de identificação, em um trabalho contínuo em torno das resistências e dos obstáculos que impedem o acesso à memória coletiva e o conhecimento do passado. Por meio de seus procedimentos e recursos expressivos, os filmes mergulham nas formas heterogêneas de manifestação do reprimido para alcançar, criticamente, seus mecanismos repetitivos: o apagamento da memória, a resignação, a denegação e a vontade de esquecer. $\mathrm{O}$ esforço de compreender essas manifestações, por meio da retomada das imagens de arquivo que passam por variações formais na mise-en-scène e na montagem, constrói uma memória que tem como referência o passado, mas que não se fixa nele propriamente, fazendo do movimento contínuo de nomeação uma das formas de elaboração da experiência catastrófica no presente. 


\section{REFERÊNCIAS}

ADORNO, Theodor W. "The Meaning of Working Through the Past". In: Critical Models: Interventions and Catchwords. New York: Columbia University Press, 2005, p. 89-103.

BENJAMIN, Walter. Obras Escolhidas I: Mágia e Técnica, Arte e Política. São Paulo: Ed. Brasiliense, 1996.

GAGNEBIN, Jeanne Marie. Lembrar escrever esquecer. São Paulo: Editora 34, 2009.

GUNNING, Tom. O retrato do corpo humano: a fotografia, os detetives e os primórdios do cinema. In: CHARNEY, Leo; SCHWARTZ, Vanessa (orgs.). O cinema e a invenção da vida moderna. Tradução de Regina Thompson. São Paulo: Cosac \& Naify, 2001, p. 39-80.

LEANDRO, Anita. "A história na primeira pessoa: em torno do método de Rithy Panh”. E-compós, Brasília, v.19, n.3, set./dez. 2016, s.p.

LEANDRO, Anita. "Uma arquivista no Camboja”. In: MAIA, Carla; FLORES, Luís Felipe. . (orgs.). O cinema de Rithy Panh. Centro Cultural Banco do Brasil, 2013, p. 185-198.

LINDEPERG, Sylvie. Le singulier destin des images d'archives contribution pour un débat, si besoin une "querelle". Disponível em: <https://www.ina-expert. $\mathrm{com} / \mathrm{e}$-dossiers-de-l-audiovisuel/le-singulier-destin-des-images-d-archives-contribution-pour-un-debat-si-besoin-unequerelle.html>, acesso em jan/2018a.

LINDEPERG, Sylvie. Des lieux de mémoire portatifs. In: Critique, Paris, $n^{\circ} 814,2015 / 3$, p. 202-214. Disponível em: <https://www.cairn.info/revue-critique-2015-3-page-202.htm >, acesso em jan/2018b.

LINDEPERG, Sylvie. Imagens de arquivos: imbricamento de olhares. Entrevista com Sylvie Lindeperg. In: Catálogo do fórum.doc. Belo Horizonte, 2010, p. 318-345.

MONDZAIN, Marie-José. A imagem pode matar? Lisboa: Editora Nova Ltda, $1^{\text {a }}$ ed., 2009.

PANH, Rithy. Sou agrimensor de memórias. In: MAIA, Carla; FLORES, Luís Felipe. (orgs.). O cinema de Rithy Panh. Centro Cultural Banco do Brasil, 2013, p. 63-74.

ROLLET, Sylvie. "Devolver o olhar”. In: MAIA, Carla; FLORES, Luís Felipe. (orgs.). O cinema de Rithy Panh. Centro Cultural Banco do Brasil, 2013, p. 199-227. 
SELIGMANN-SILVA, Márcio. A atualidade de Walter Benjamin e Theodor W. Adorno. 2a edição. Rio de Janeiro: Civilização Brasileira, 2010.

SELIGMANN-SILVA, Márcio. A história como trauma. In: NESTROVSKI, Arthur; SELIGMANN-SILVA, Márcio (orgs). Catástrofe e representação: ensaios. São Paulo: Escuta, 2000, p. 73-98.

Recebido em: 30/09/2020

Aceito em: 05/07/2021 